\title{
Leading Difficult Conversations Series \#2: Preparing for the Conversation ${ }^{1}$
}

\author{
Christy C. Chiarelli
}

\section{Introduction}

This publication series is designed to equip leaders with strategies and tactics to use when they are tasked with having a difficult conversation. Leading a team can be a very rewarding experience. Witnessing the professional growth of individuals on the team, celebrating team success, and benefiting from the synergistic ideas of a group are all potential highlights of serving as a leader. However, leadership does not come without its challenges. One such challenge is the responsibility of having difficult conversations. Leaders are often required to have necessary conversations that are not always easy. Stone, Patton and Heen (1999) provide a simple definition for these types of conversations: "difficult conversations are anything you find it hard to talk about" (p. xxvii). Patterson et al. (2012) provide additional descriptors of difficult conversations: (1) two or more individuals have opposing opinions; (2) strong emotions are present; and (3) the stakes related to the outcome are high.

Many leaders prefer to avoid difficult conversations, hoping the issue will resolve itself (Patterson et al., 2012; Farrell, 2015). However, avoiding difficult conversations is a leadership weakness and a failure to one's followers. Leaders ultimately serve others more effectively if they seek to increase their understanding and implementation of difficult dialogue skills.
A popular book that examines the topic of difficult conversations is Crucial Conversations: Tools for Talking When Stakes are High. In this book, the authors pair concise ideas with applicable tools. When approaching difficult conversations, leaders are encouraged to examine themselves prior to engaging in a hard conversation, because ultimately, a person can only change themself (Patterson et al., 2012). In this Leading Difficult Conversations series, the first topic to explore is preparing for the conversation. The components of proper preparation include clearly defining the issue and considering the motive behind the conversation.

\section{Defining the Issue}

When faced with the realization a difficult conversation needs to happen, it is important for a leader to prepare for the conversation. Sometimes issues arise with colleagues or subordinates due to conflicting personality traits. Prior to engaging in a difficult conversation, the leader should determine if the issue is related to conflicting personality characteristics or performance issues. While personalities can be frustrating, professional conversations should be focused on performance or behavior issues (Farrell, 2015). Due to the emotions associated with conflict, individuals tend to employ a fight-or-flight response, which does not promote healthy dialogue and often ends with an undesirable outcome. Neither a fight nor flight response can lead to healthy dialogue. By taking the necessary preparation time, a leader can avoid the flight-or-fight impulses that

1. This document is AEC715, one of a series of the Department of Agricultural Education and Communication, UF/IFAS Extension. Original publication date January 2021. Visit the EDIS website at https://edis.ifas.ufl.edu for the currently supported version of this publication.

2. Christy Chiarelli, Extension scientist, leadership development, Department of Agricultural Education and Communication, UF/IFAS Extension, Gainesville, FL 32611.

The Institute of Food and Agricultural Sciences (IFAS) is an Equal Opportunity Institution authorized to provide research, educational information and other services

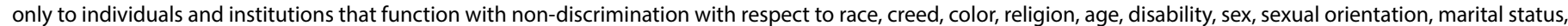

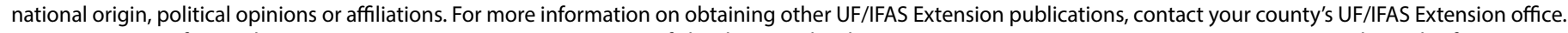
U.S. Department of Agriculture, UF/IFAS Extension Service, University of Florida, IFAS, Florida A \& M University Cooperative Extension Program, and Boards of County Commissioners Cooperating. Nick T. Place, dean for UF/IFAS Extension. 
often come with unexpected conflict. One strategy is to force your brain to see beyond binary choices, such as fight or flight. Rather, Patterson et al. (2012) encourage leaders to search for the "elusive and" in their internal monologue while preparing for the conversation (p. 46). The "elusive and" refers to leaders defining the outcome they want and the outcome they do not want. Then, leaders combine those outcomes with the word "and"-for example, "how can I have an honest conversation with Mary about being consistently late for work and avoid hurting her feelings?" Forcing your brain to think beyond binary choices helps to clarify the issue needing to be addressed.

\section{Considering the Motive}

A motive is defined as "something (such as a need or desire) that causes a person to act" (Merriam-Webster, 2020). If a leader's motives for having a conversation are not honorable, the conversation is likely to become increasingly difficult. Emotions play an important role in determining an individual's behavior (Hwang and Matsumoto, 2017). Leaders are not immune from experiencing and being affected by their emotions. In fact, leaders must acknowledge their emotional response to the issue and consider its impact on their perspective of the situation (Overton and Lowery, 2013).

When preparing for a difficult conversation, leaders should examine the true motive of the conversation. Patterson et al. (2012) categorize motives into two categories: dialogue killers and dialogue promoters. Dialogue is defined as "the free flow of meaning between two or more people" (Patterson et al., 2012, p. 23). A leader's motive entering a difficult conversation can be one that promotes dialogue or one that is harmful to dialogue. Successful difficult conversations should have dialogue promoters as the foundation of the conversation motive. Patterson et al. (2012) classify the motives below into categories of dialogue killers or dialogue promoters. If your motive in having the conversation falls in the category of a dialogue killer, the chances of a successful difficult conversation are slim. However, if your motive falls in the category of dialogue promoters, there is a stronger chance for a healthy dialogue to emerge around the issue at hand.

\begin{tabular}{|l|l|}
\hline \multicolumn{1}{|c|}{ Dialogue Killers } & \multicolumn{1}{c|}{ Dialogue Promoters } \\
\hline Protect Your Ego/Look Good & Learn \\
\hline Keep the Peace/Avoid Conflict & Find the Truth \\
\hline Win/Be Right & Make Effective Decisions \\
\hline Punish & Get Results \\
\hline & Build Relationships \\
\hline
\end{tabular}

Another benefit of solidifying the goal and motive behind the conversation is to avoid being distracted by "side issues in the conversation" (Farrell, 2015, p. 305). Side issues can arise during the conversation when motives inadvertently change. Leaders may begin a conversation in a positive manner, but when challenged, motives may shift from dialogue promoters to dialogue killers. In this case, the leader shifts their motive to winning, punishing, or keeping the peace in the conversation instead of the original intended goal (Patterson et al., 2012). Knowing the issue and motive in advance allows a leader to stay focused on what they really want during the conversation. While it may seem obvious to be prepared for the conversation by considering the intended goal and motive of a conversation, this step is rarely done (Overton \& Lowry, 2013).

\section{Summary}

Difficult conversations are a necessary component of effective leadership. Success begins with properly preparing for the conversation by defining the issue, examining the motive, and understanding one's communication style under stress. While hard conversations may not be a highlight of a leader's experience, the encouraging news is dialogue skills are learnable (Patterson et al., 2012). The next publication in the Leading Difficult Conversations series will discuss creating a safe conversation environment and exploring tactics to keep the conversation moving forward.

\section{References}

Barr, R. (2013). Performance management: Making difficult conversations easy and managing soft skills. In R. Farrell \& K. Schlesinger (Eds.), Managing in the middle. Chicago: American Library Association.

Farrell, M. (Column Editor). (2015). Difficult conversations. Journal of Library Administration, 55(4), 302-311. https:// doi.org/10.1080/01930826.2015.1038931

Hwang, H., \& Matsumoto, D. (2017). Functions of emotions. In R. Biswas-Diener \& E. Diener (Eds.), Noba textbook series: Psychology. Champaign, IL: DEF publishers. https://nobaproject.com/

Merriam-Webster. (n.d.). Motive. In Merriam-Webster.com online dictionary. Retrieved July 21, 2020, from https:// www.merriam-webster.com/dictionary/motive

Overton, A. R., \& Lowry, A. C. (2013). Conflict management: Difficult conversations with difficult people. Clinics in Colon and Rectal Surgery, 26(4), 259-264. https://doi. org/10.1055/s-0033-1356728 
Patterson, K., Grenny, J., McMillan, R., \& Switzler, A. (2012). Crucial conversations: Tools for talking when the stakes are high. McGraw-Hill.

Stone, D., Patton, B. and Heen, S. (1999). Difficult conversa-

tions: How to discuss what matters most. New York, NY:

Penguin. 